УДК 62-6

\title{
АНАЛИЗ ПРЕИМУЩЕСТВ СИСТЕМ ОБЕСПЕЧЕНИЯ ТЕПЛОВОГО РЕЖИМА ЛОКАЛЬНЫХ РАБОЧИХ ЗОН НА ОСНОВЕ ГАЗОВЫХ ИНФРАКРАСНЫХ ИЗЛУЧАТЕЛЕЙ ПО СРАВНЕНИЮ С ТРАДИЦИОННЫМИ КОНВЕКТИВНЫМИ СИСТЕМАМИ ОТОПЛЕНИЯ
}

\author{
Максимов Вячеслав Иванович1, \\ elf@tpu.ru
}

\author{
Нагорнова Татьяна Александровна', \\ tania@tpu.ru
}

Куриленко Николай Ильич²,
kurilenkoni@tyuiu ru

\author{
Волошко Иван Валентинович, \\ iv_voloshko@mail.ru \\ 1 Национальный исследовательский Томский политехнический университет, \\ Россия, 634050, г. Томск, пр. Ленина, 30. \\ 2 Тюменский индустриальный университет, \\ Россия, 625000, г. Тюмень, ул. Володарского, 38. \\ 3 «Теплотранзит Караганда», \\ Казахстан, 100017, г. Караганда, ул. Пригородная, 9/2.
}

\begin{abstract}
Актуальность исследования обусловлена снижением затрат тепловой энергии на обеспечения теплового режима локальных рабочих зон в производственных помещениях, характерные размеры которых существенно (многократно) превышают размеры этих зон. Проблемы энергосбережения являются актуальными уже многие десятилетия по целому ряду объективных причин, но пока нет оснований для вывода о том, что решена большая часть задач энергосбережения, возникающих в производственной и социальной сферах. Известный достаточно давно способ локального «теплоснабжения» рабочего места относительно малых размеров с использованием газовых инфракрасных излучателей до последнего времени используется мало в связи с отсутствием научно-технической базы, обеспечивающей проведение опытно-конструкторских работ по созданию систем обеспечения теплового режима локальных рабочих мест на базе газовых инфрракрасных излучателей.

Цель: анализ энергоэффрективности газовых инфракрасных излучателей как основных элементов систем обеспечения теплового режима локальных рабочих зон.

объекты: крупногабаритное помещение, обогреваемое газовым инфрракрасным излучателем.

Методы: экспериментальные измерения температур поверхности пола термопарами типа хромель-алюмель с толщиной спая 0,08 мм и фиксация данных при помощи модуля измерения температуры NI 9214 формы National Instruments; математическое моделирование процессов переноса тепла в многослойном полу.

Результаты. Приведены результаты экспериментальных и теоретических исследований, выполненных с целью оценки эфрфективности использования таких систем. Эксперименты проведены в специальном боксе, воспроизводящем условия подвода теплоты от излучателя к рабочему месту малых размеров. Проведены измерения температур поверхности пола в десяти характерных точках при работе достаточно типичного излучателя средней мощности. Результаты экспериментов использовались в качестве краевых условий на границе раздела «воздух - поверхность пола бокса» при решении задач теплопроводности. По результатам экспериментальных и теоретических исследований обоснованы преимущества (по сравнению с традиционными конвективными системами отопления даже малогабаритных производственных помещений) систем обеспечения теплового режима локальных рабочих зон на базе газовых инфрракрасных излучателей. Сущность этих преимуществ состоит в том, что при использовании излучателей регламентный тепловой режим обеспечивается без затрат энергии на нагрев ограждающих конструкций и воздуха за пределами рабочей зоны (которая может быть в десятки раз меньще по объему всего производственного помещения).
\end{abstract}

\section{Ключевые слова:}

Энергосбережение, газовые инфрракрасные излучатели, теплоперенос, термопарные измерения, распределения температур, энергоэфффективность.

\section{Введение}

Газовые инфракрасные излучатели (ГИИ) [1-4] в последние годы всё чаще рассматриваются как эффективные системы обеспечения теплового режима локальных рабочих мест [5-9]. Такие излучатели не являются источником газового отопления в традиционном понимании этого термина. Они нагревают не воду, которая затем перемещается в специальных системах отопления. Газовые инфракрасные излучатели нагре- вают поверхности пола и ограждающих конструкций (если они есть в зоне воздействия ГИИ), а затем эти нагретые поверхности передают теплоту воздуху, который в результате термогравитационной конвекции циркулирует в зоне воздействия ГИИ. Они не занимают полезного пространства и могут охватывать своим излучением избирательную (локальную) площадь помещения. Основное преимущество - возможность создания регламентного теплового режима в малом по 
объему пространстве большого производственного помещения. По результатам теоретических (с использованием моделей [10]) [10-12] и экспериментальных $[13,14]$ исследований установлен механизм теплопереноса в зонах поступления теплоты в результате работы ГИИ [12], существенно отличающийся от механизма теплопереноса при работе традиционных конвективных систем отопления [15-17]. Установлено, что при работе газовых инфракрасных излучателей нагрев воздуха относительно малого объёма, соответствующего области рабочей зоны, происходит вследствие термогравитационной конвекции $[10,11,13]$. Нагретый до относительно высоких температур пол помещения передаёт теплоту воздуху, который поднимается вверх и обеспечивает при необходимых параметрах ГИИ регламентный тепловой режим малогабаритной рабочей зоны [18]. Системы обеспечения теплового режима локальных рабочих зон на основе ГИИ могут быть достаточно эффективны $[5,19]$. Но их широкое внедрение сдерживается до последнего времени в связи с тем, что нет объективных (на основании экспериментальных данных) оценок как энергетической, так и экономической эффективности использования таких систем $[15,20,21]$. По этим причинам целью работы является анализ энергоэффективности ГИИ как основных элементов систем обеспечения теплового режима локальных рабочих зон. Для достижения цели проведены экспериментальные и теоретические исследования рассматриваемых процессов теплопереноса при работе таких излучателей.

Решена задача (первая) установления доли вырабатываемой ГИИ теплоты, непосредственно затрачиваемой на нагрев воздуха рабочей зоны. Для решения этой задачи необходимо определение теплоты, аккумулируемой полом помещения - основным инструментом превращения лучистой энергии, вырабатываемой ГИИ, в теплоту воздуха рабочей зоны (вторая задача). Решение второй задачи возможно в результате решения уравнения энергии для слоя напольного покрытия определённой толщины (третья задача) при известных тепловых потоках, генерируемых ГИИ (q) к поверхности пола, или его температуры $T_{f}$. Третья же задача может быть решена после экспериментального определения нескольких типичных для практики вариантов связи $q$ и температуры поверхности пола. Такие связи $q$ и $T_{f}$ дают возможность также верифицировать результаты математического моделирования

\section{Методика экспериментов}

Для достижения поставленной цели использовалась экспериментальная установка (рис. 1), основными элементами которой являются: 1) газовый инфракрасный излучатель - ГИИ-5 светлого типа производства фирмы «Сибшванк» с номинальной тепловой мощностью 5 кВт, в котором происходит выделение лучистого тепла в инфракрасном диапазоне на керамической пластине, нагреваемой теплотой сгорания природного газа в смесительной камере, расположенной в непосредственной близости от нее; 2) источник газа; 3) модель объекта теплоснабжения; 4) термопары типа хромель-алюмель с изолирующим покрыти- ем из фторполимера PFA (толщина спая 0,08 мм); 5) аналого-цифровой преобразователь (АЦП) - сетевой преобразователь National Instruments с DAQ-9181, предназначенный для управления тактированием, синхронизацией и передачей данных с 16-канального, 32битного изотермического модуля измерения температуры NI-9214 фирмы National Instruments; 6) персональная электронно-вычислительная машина (ПЭВМ).

Температурные измерения с погрешностью $0,37^{\circ} \mathrm{C}$ через аналого-цифровой преобразователь передавались на компьютер каждую секунду.

Эксперименты проводились в двух закрытых помещениях с различной поверхностью пола: белая керамическая плитка и темно-серый бетон. Габаритные размеры экспериментальных помещений 10,2×4,9×4,4 и $8,7 \times 6,0 \times 3,4$ м, высота от пола до ГИИ $-2,975$ и 2,6 м, соответственно. Стены помещения кирпичные толщиной 70 см с пластиковыми оконными проемами $\left(R_{\text {кирпич }}=0,502 \mathrm{M}^{2} \cdot \mathrm{K} / \mathrm{BT}, R_{\text {окно }}=0,51 \mathrm{M}^{2} \cdot \mathrm{K} / \mathrm{BT}\right)$.

Разные поверхности пола, являющегося своеобразным преобразователем энергии излучения в теплоту, аккумулированную воздухом [6], в экспериментах использовались для того, чтобы оценить влияние состояния нагреваемой ГИИ поверхности на тепловой режим локальной рабочей зоны. Можно отметить, что в обычных условиях, соответствующих нормам и правилам промышленной санитарии [22], воздух производственных помещений не должен содержать частиц пыли, а его влажность должна быть минимально регламентированной.

По этим причинам воздух производственных помещений не может быть нагрет непосредственно излучением в подавляющем большинстве практически значимых вариантов. Нагрев воздуха в локальной рабочей зоне осуществляется за счет излучения опосредованно - нагревается до достаточно высоких $\left(20-25{ }^{\circ} \mathrm{C}\right)$ температур тонкий приповерхностный слой пола помещения, и после этого за счет конвекции и теплопроводности уже воздух $[9,23]$. При проведении экспериментов интенсивность нагрева последнего зависит от температуры поверхности пола. Начальная температура воздуха в помещении варьировалась от 7 до $18^{\circ} \mathrm{C}$, при этом температура окружающей среды изменялась от -15 до $-35^{\circ} \mathrm{C}$. Во время проведения экспериментов ГИИ находился в стационарном положении на контролируемых расстояниях от поверхности нагрева. Термопары размещались на поверхности пола и ориентировались по двум координатным направлениям (рис. 2). Для улучшения термического контакта термопар с поверхностью пола и защиты их от переизлучения использовалась термопаста КПТ-8. Аналого-цифровой преобразователь и система сбора данных находились на расстоянии 4 м от поверхности измерения, на теплоизолирующей подкладке, и также с защитой от переизлучения для термостатирования встроенного в них холодного спая. Персональная электронно-вычислительная машина, запорно-регулирующее оборудование, а также баллон с газом располагались вне исследуемого помещения для исключения их влияния на тепловой режим в исследуемой области. Сигналы с термопар 
регистрировались измерительным комплексом (аналого-цифровой преобразователь NI 9214 и модуль ввода/вывода NI cDAQ 9171 National Instruments) с временным интервалом не более 1 с. Полученные значения температур передавались на ПЭВМ, где обрабатывались и сохранялись в файл.

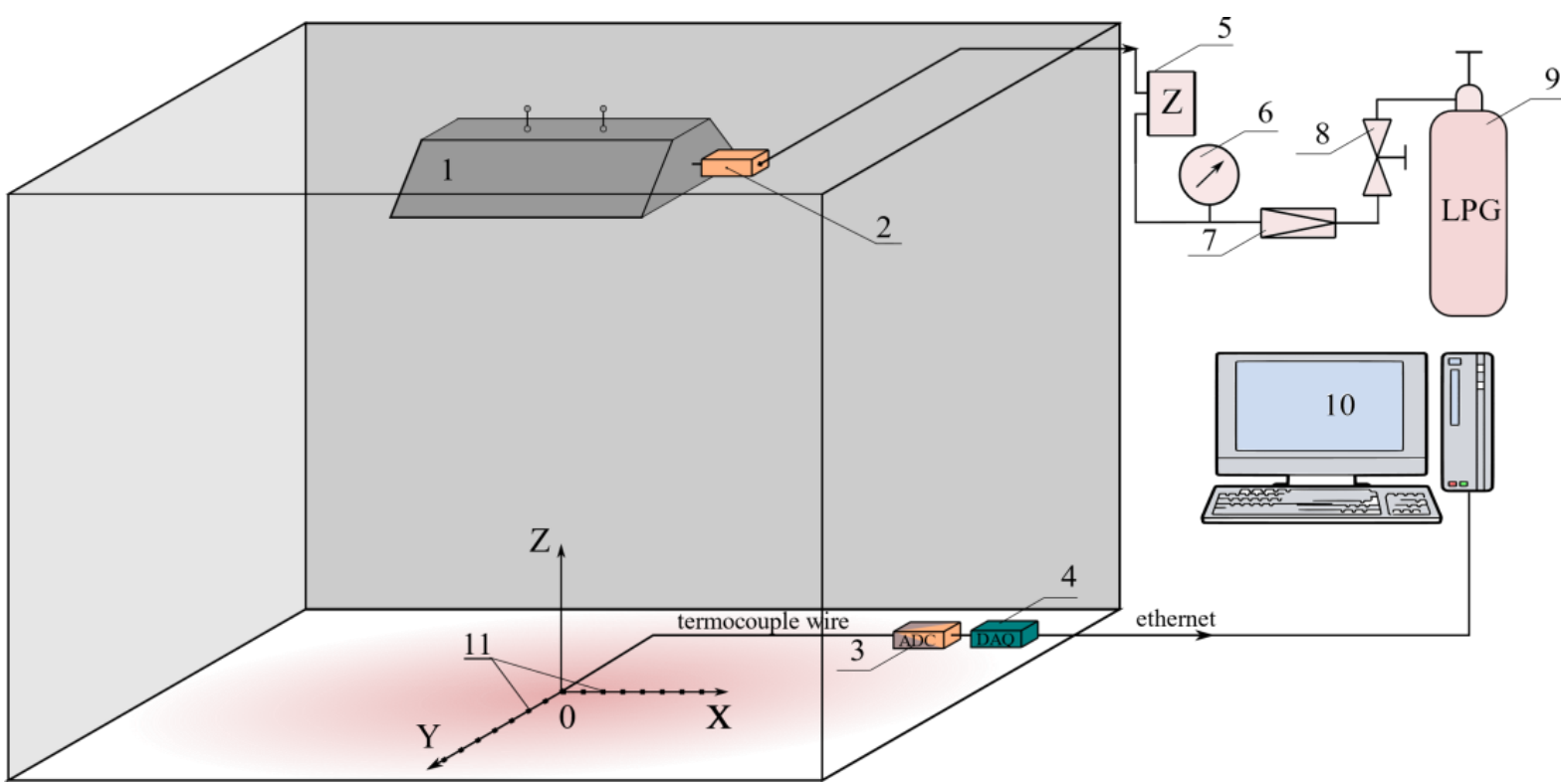

Рис. 1. Схематичное изображение области проведения экспериментов: 1 - ГИИ; 2 - блок управления ГИИ; 3 - аналого-иифровой преобразователь; 4 - система сбора данных; 5 - газовый расходомер; 6 - манометр; 7 - регулятор давления газа; 8 - основное отключающее устройство; 9 - газовый баллон; 10 - компьютер; 11 термопары

Fig. 1. Schematic representation of the experimental area: 1 - GIE; 2 - GIE control unit; 3 - analog-to-digital converter; 4 -data acquisition system; 5 - gas flow meter; 6 - pressure gauge; 7 - gas pressure regulator; 8 - main shut-off device; 9 -gas cylinder; 10 - computer; 11 -thermocouples

С целью обеспечения возможности оценки случайных ошибок измерений все эксперименты при фиксированных условиях их выполнения проводились не менее трех раз. После этого вычислялись среднеквадратические отклонения и соответствующие коэффициенты вариации. Значения последних во всех экспериментах не превышали 1 \%. Статистическая обработка результатов измерений была необходима в связи с возможностью влияния на показания средств измерений факторов второго и третьего уровней значимости (влажности воздуха, атмосферного давления, изменения температуры внешней среды в течение длительных экспериментов). Масштабы влияния этих факторов незначительны, но в соответ- ствии с общими положениями теории ошибок экспериментальных исследований их необходимо оценивать.

При планировании, организации и проведении экспериментов рассматривались наиболее неблагоприятные для формирования теплового режима локальной рабочей зоны условия - по периметру зоны не устанавливались никакие специальные ограждающие конструкции, которые могли снизить тепловые потери в область вне рабочей зоны. В экспериментах воспроизводились условия, достаточно типичные для локальных рабочих зон в крупногабаритных помещениях, производственные площади которых используются в небольшой степени [15].

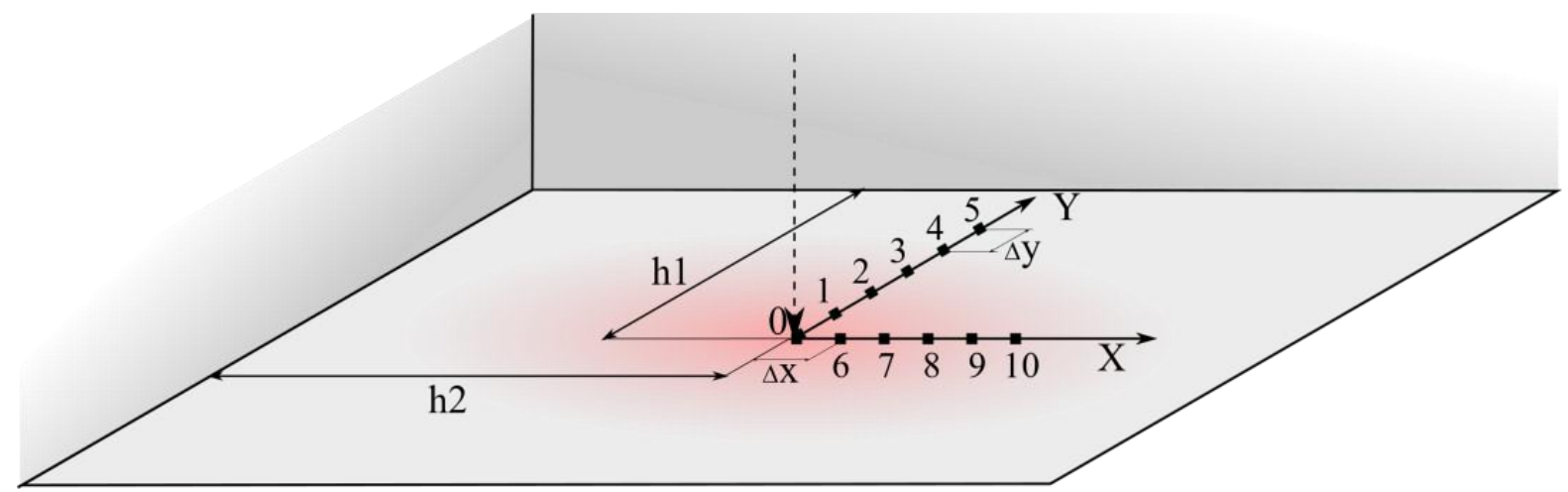

Рис. 2. Схема размещения термопар в области проведения экспериментов

Fig. 2. Diagram of the thermocouples in the field of the experiments 
За начало координат принималась проекция центра симметрии ГИИ. Расстояния между двумя соседними термопарами одного и того же координатного направления составляли $0,2 \mathrm{~m}$.

Следует отметить, что локальные рабочие места могут быть расположены в производственных помещениях, характерные размеры которых (и, соответственно, площади и объемы) могут многократно (в десять и более раз) превышать характерные размеры рабочей зоны [15]. По этим причинам условия реализации режима термогравитационной конвекции будут несколько отличаться при подводе лучистой энергии к рабочему месту, расположенному в помещении площадью 200 или $2000 \mathrm{~m}^{2}$, если не принимать специальных мер. Размеры бокса, в котором проводились ис- следования, были выбраны средними, чтобы обеспечить возможность объективной интерпретации результатов экспериментов как для небольших, так и для очень больших производственных помещений. При этом принимались во внимание не только площади, но и объемы помещений, т. к. теплый воздух распространяется по всем трем координатным направлениям в условиях работы газовых инфракрасных излучателей.

\section{Результаты экспериментов}

Установленные в экспериментах типичные зависимости температур в точках расположения спаев термопар на поверхностях пола от времени представлены на рис. 3, 4.

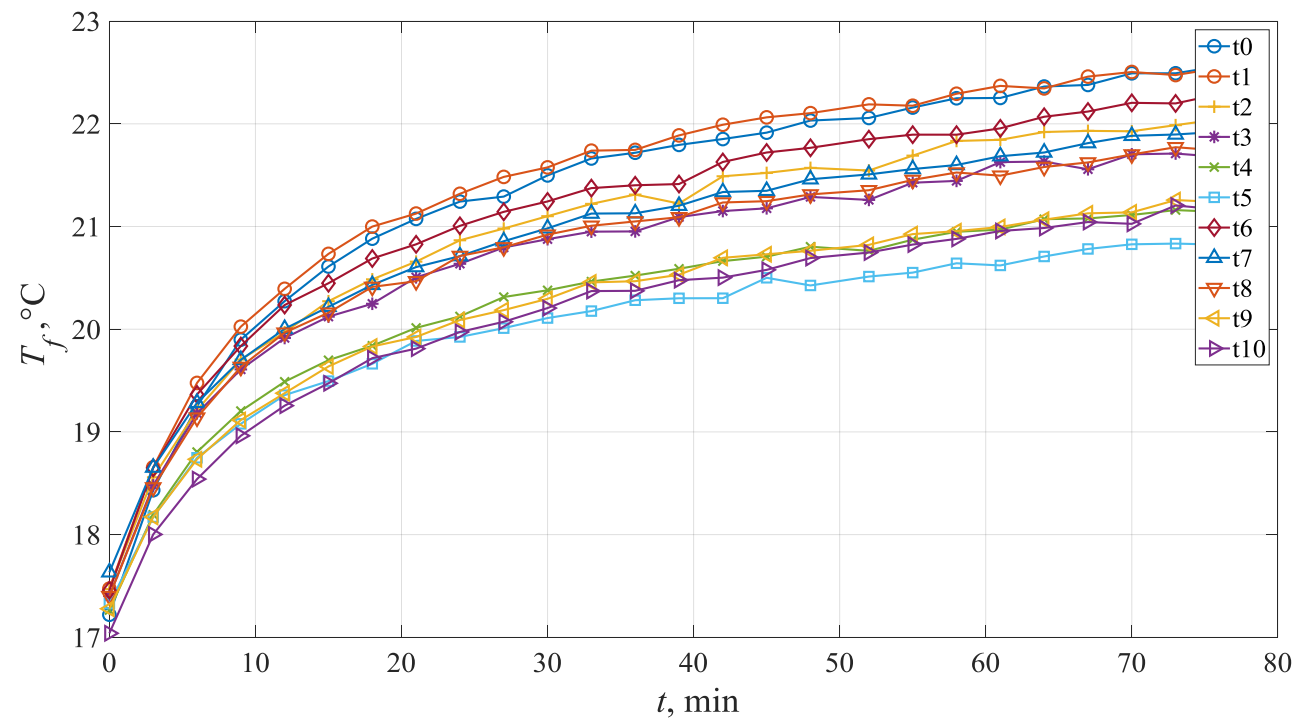

Рис. 3. Изменения с ростом времени температур в десяти точках поверхности пола (покрытой керамической плиткой). Цифры соответствуют номерам термопар на рис. 2

Fig. 3. Changes in temperature with increasing time at ten points of the floor surface (covered with the ceramic tiles). The numbers correspond to the numbers of the thermocouples in Fig. 2

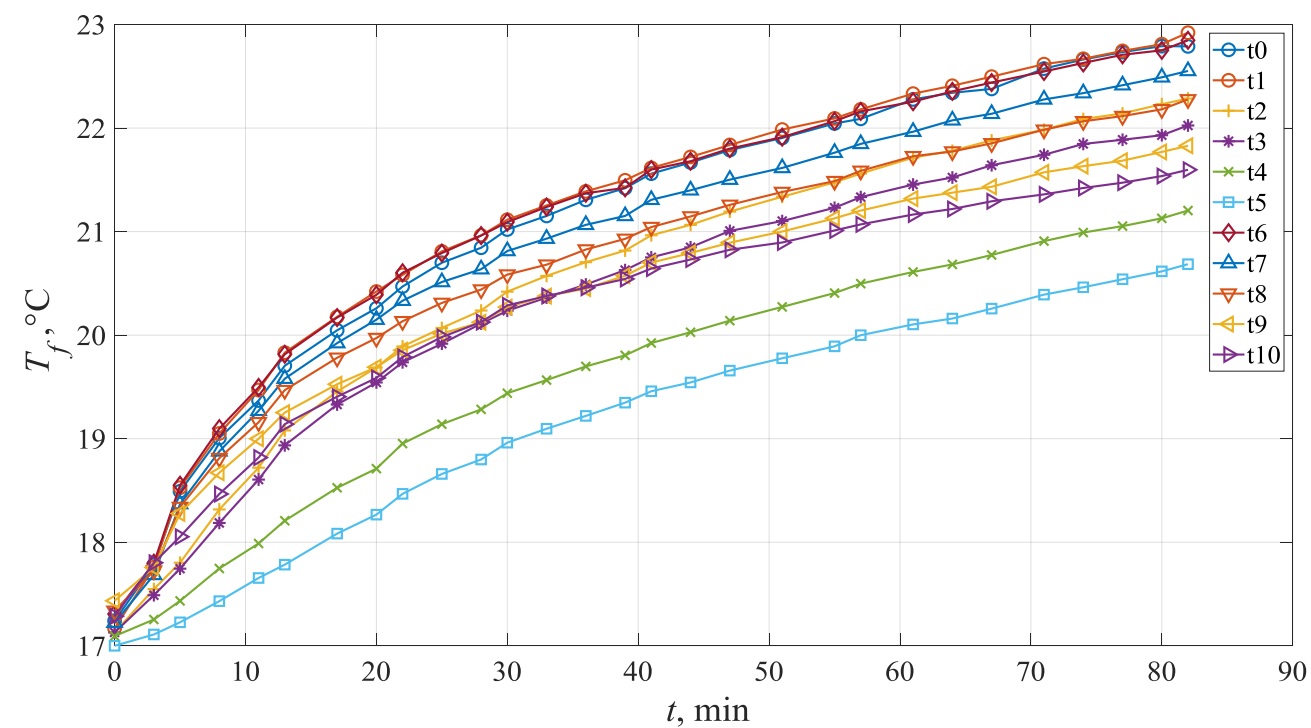

Рис. 4. Изменения с ростом времени температур в десяти точках поверхности бетонного пола. Цифры соответствуют номерам термопар на рис. 2

Fig. 4. Changes in temperature with increasing time at ten points on the surface of the concrete floor. The numbers correspond to the numbers of the thermocouples in Fig. 2 
Можно отметить, что все приведенные на рис. 3, 4 зависимости $T_{f}(X)$ являются в некоторой степени немонотонными - отклонения в несколько десятых долей градуса на интервалах времени в несколько минут достаточно типичны для большинства показаний термопар. Такой вид зависимостей $T_{f}(t)$ косвенно подтверждает, скорее всего, турбулентный характер термогравитационного течения воздуха вблизи поверхности пола. Вычислены числа $\mathrm{Gr}$, по которым обычно выполняется [24] анализ режима термогравитационного течения воздуха. При исходных данных $L=5 \mathrm{~m}, V=224 \mathrm{~m}^{3}$ число $\mathrm{Gr}$ для типичных исследуемых режимов составляет около $10^{12}$. Такое значение Gr по теории [24] соответствует явно выраженному турбулентному режиму свободной конвекции. При этом масштабы этих мини флуктуаций температуры поверхности $\left(0,5-0,7{ }^{\circ} \mathrm{C}\right)$ зависят от положения спая термопары - чем ближе он к центру, тем больше локальные отклонения значений $T_{f}$ от средних. Последнее иллюстрирует влияние градиентов $T_{f}$ по двум координатным направлениям $(X$ и $Y)$ на степень турбулизации течения нагретого в результате теплоотвода от пола тонкого слоя воздуха, поднимающегося вверх и формирующего тепловой режим рабочей зоны на высоте до двух метров $[6,14]$. Как видно из рис. 3,4 , динамика изменения полей температур пола со временем для помещений с различным половым покрытием почти идентична. Максимальная температура поверхности пола достигается, как и можно было ожидать, в точке, соответствующей проекции оси симметрии ГИИ.

На рис. 5-8 представлены типичные распределения температур по координатам $X$ и $Y$ для бетонного пола и пола, покрытого керамической плиткой, в характерные моменты времени. Эксперименты показали, что за 80 минут работы ГИИ температура поверхности пола поднимается на $5-6{ }^{\circ} \mathrm{C}$. В дальнейшем за 60 минут она изменяется менее чем на 1 градус. Поэтому на рисунках приведены результаты экспериментов в диапазоне изменения времени до 80 мин.
Необходимо отметить, что методическая погрешность термопарных измерений составляет не более $1 \%$. Поэтому зарегистрированные термопарами в начале эксперимента (при $t=0$ ) отклонения в $\pm 0,5^{\circ} \mathrm{C}$ являются, скорее всего, следствием методических погрешностей, а также случайных ошибок, обусловленных неконтролируемыми малозначимыми факторами (неоднородность железобетона, загрязнения и неровности его поверхности и др.). Так, например, показания термопар, как показал анализ, зависят в некоторой степени от вида материала в приповерхностном слое, прилегающем к месту закрепления термопары. Это может быть сталь арматуры железобетона, камень или песок. Соответственно, теплофизические свойства стали значительно отличаются (например, теплопроводность) от аналогичного свойства камня. Поэтому возможны небольшие $\left( \pm 0,6^{\circ} \mathrm{C}\right)$, но заметные отклонения $T_{f}(X)$.

Экспериментально установлено, что по мере удаления термопар от центра симметрии проекции ГИИ значения температур уменьшаются на $0,5-1,0{ }^{\circ} \mathrm{C}$ (рис. 5-8). Через 50 мин после включения ГИИ температура в центре зоны измерений $T_{f}$ в обоих случаях становится равной $22{ }^{\circ} \mathrm{C}$. Это объясняется тем, что у бетона и керамической плитки схожие теплофизические свойства, а коэффициент излучения в инфракрасном диапазоне одинаков $(\varepsilon=0,95[25,26])$. Можно сделать вывод о том, что распределение температуры поверхности пола помещения, обогреваемого газовым инфракрасным излучателем, не зависит от коэффициента излучения напольного покрытия в оптическом диапазоне (по сути цвета: бетон черный, керамическая плитка белая). Установленные в экспериментах закономерности позволяют обосновать гипотезу, что перенос энергии в системе «излучатель - воздух - напольное покрытие» происходит, скорее всего, за счет всех механизмов теплопереноса $[10,27]$. Также можно сделать вывод о том, что изменение, например, геометрических характеристик крупногабаритных помещений (объёма) на 20 \% практически не должно влиять на распределение температур поверхности пола, нагреваемого ГИИ.

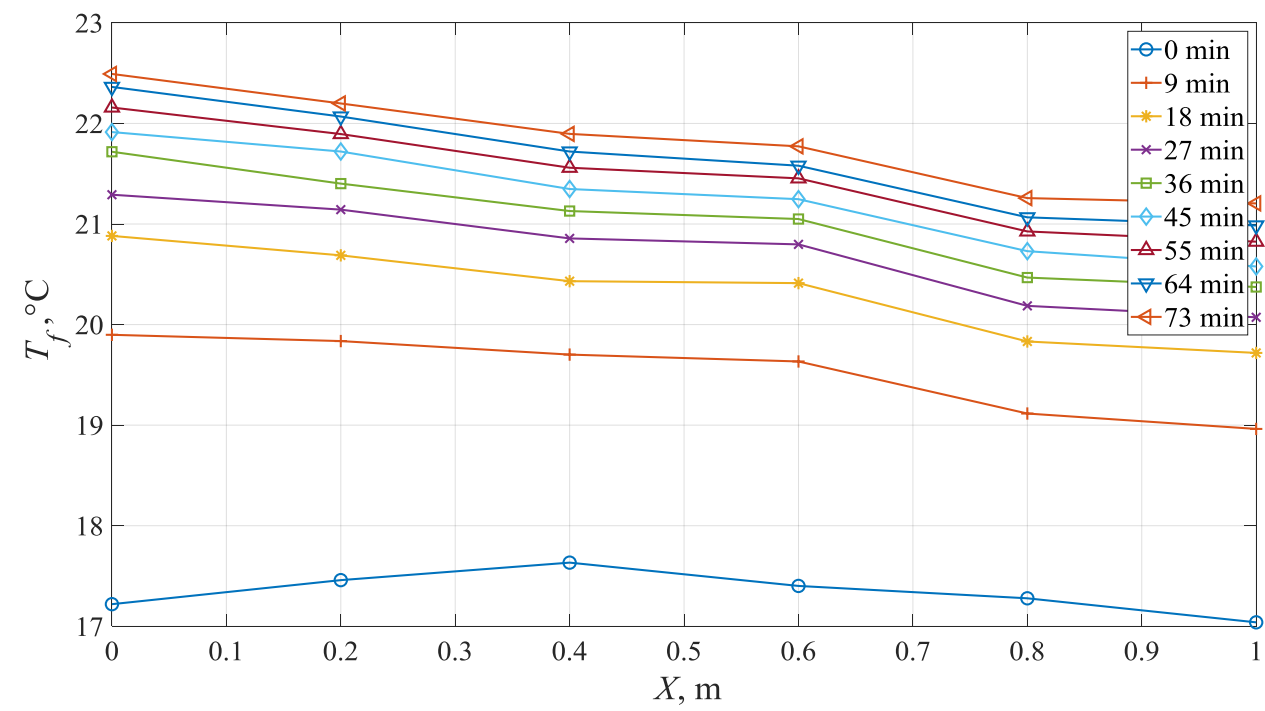

Рис. 5. Распределение температуры поверхности пола (керамическая плитка) по координатному направлению $X$ в характерные моменты времени

Fig. 5. Floor surface temperature distribution (the ceramic tile) in the coordinate direction $X$ at the characteristic times 


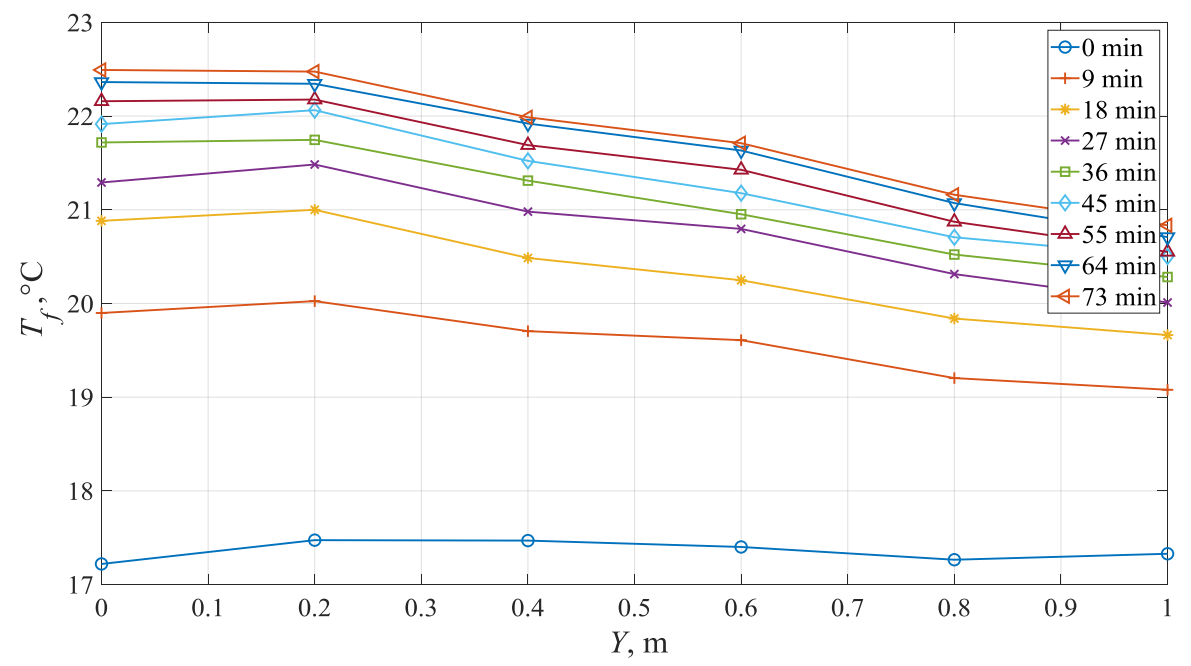

Рис. 6. Распределение температуры поверхности пола (керамическая плитка) по координатному направлению $Ү$ в характерные моменты времени

Fig. 6. Floor surface temperature distribution (the ceramic tile) in the coordinate direction $Y$ at the characteristic times

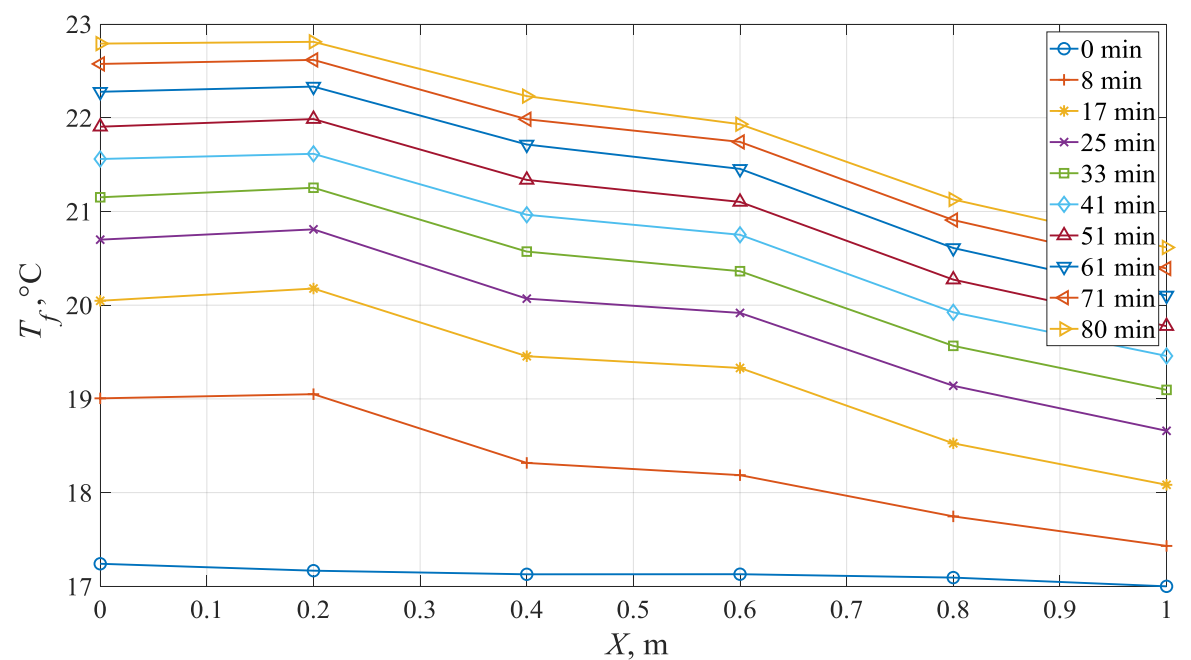

Рис. 7. Распределение температуры поверхности пола (бетон) по координатному направлению Х в характерные моменты времени

Fig. 7. Floor surface temperature distribution (concrete) in the coordinate direction $X$ at the characteristic times

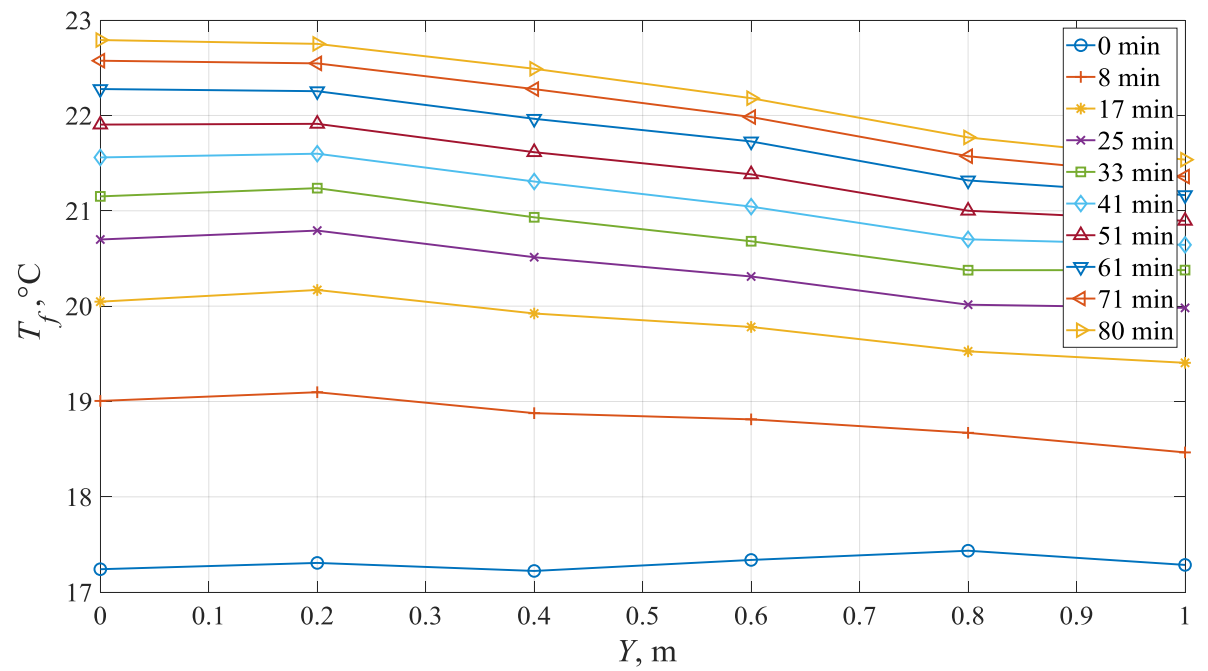

Рис. 8. Распределение температуры поверхности пола (бетон) по координатному направлению $Y$ в характерные моменты времени

Fig. 8. Floor surface temperature distribution (concrete) in the coordinate direction $Y$ at the characteristic times 
Размер помещения по высоте не влияет на распределение температур, т. к. излучатель, нагретый до высоких температур, препятствует движению воздуха вверх и циркуляционные движения происходят в области, ограниченной снизу полом, а сверху излучателем. Поперечные размеры помещения также не оказывают значимого влияния на распределение температуры поверхности, т. к. зона воздействия излучателя ограничена. Так, например, при высоте его размещения 2,95 м и мощности 5 кВт площадь нагреваемой на 1 K поверхности, по сравнению с начальной, составляет не более $20 \mathrm{~m}^{2}$ (радиус такой площадки около 2,5 м).

Следует отметить, что размещение излучателя всегда возможно на любой высоте (на любом расстоянии от рабочей зоны). Теплый воздух, нагреваемый в результате теплоотдачи от нагретого излучением пола, при движении вверх не может подняться выше ГИИ, т. к. воздух вокруг последнего нагрет до высоких (много больше, например, $23{ }^{\circ} \mathrm{C}$ ) температур. Поэтому циркуляционные течения в результате работы
ГИИ формируются в области между поверхностью пола и излучателем, горячий воздух вокруг которого препятствует движению теплого воздуха с существенно меньшей температурой, который поднимается в результате термогравитационной конвекции вверх, а затем после охлаждения опускается вниз. По этой причине общая высота помещения не играет роли в формировании теплового режима локальной рабочей зоны.

\section{Физическая и математическая постановки задачи}

Для установления доли вырабатываемой ГИИ теплоты, непосредственно затрачиваемой на нагрев воздуха рабочей зоны, определена теплота, аккумулируемая полом помещения. Для этого решено уравнение энергии для двухслойного (рис. 9, a) и однослойного (рис. 9, б) пола соответствующей эксперименту толщины при установленных экспериментально тепловых потоках $\left(q_{t}\right)$ к поверхности пола (табл. 1), полученных ранее $[6,14]$.
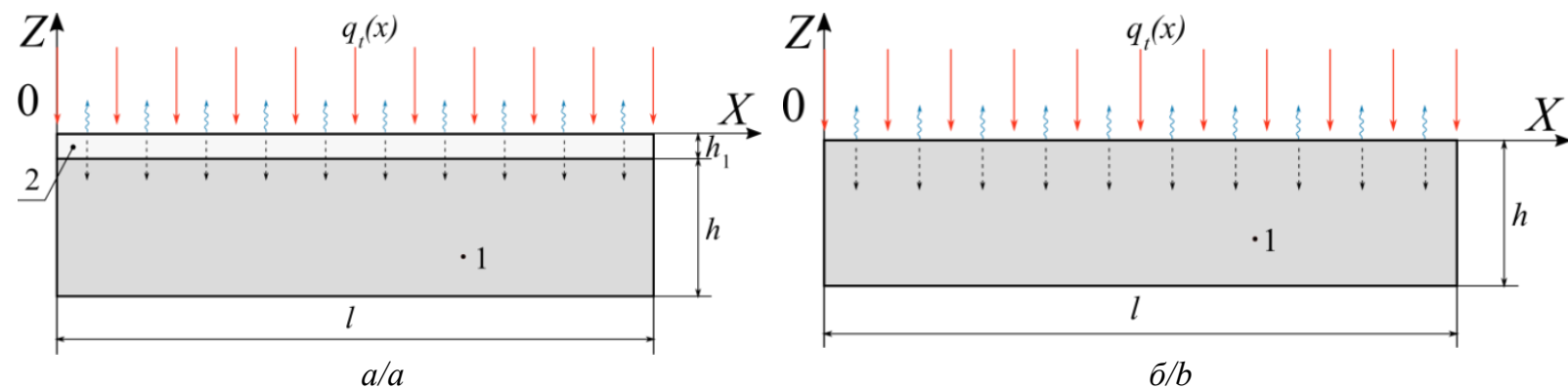

$\sigma / b$

Pис. 9. Область решения задачи для двухслойного (а) и однослойного пола (б): 1 - бетон, 2 - керамическая плитка

Fig. 9. Solution area for the two-layer $(a)$ and single-layer floors $(b)$ : 1 - concrete, 2 -ceramic tile

Таблица 1. Распределение удельного теплового потока по поверхности бетонного пола в сечении $Y=0$ при $0<X<2,3$ м (рис. 1$)$

Table 1. Specific heat flux distribution over the surface of the concrete floor in the section $Y=0$ at $0<X<2,3$ m (Fig. 1)

\begin{tabular}{|c|c|c|c|c|c|c|c|}
\hline $\begin{array}{c}\text { Координата } X, \mathrm{~m} \\
\text { Coordinate } X, \mathrm{~m}\end{array}$ & 0 & 0,5 & 0,8 & 1,3 & 1,7 & 2,1 & 2,3 \\
\hline$q, \mathrm{BT} / \mathrm{m}^{2} / \mathrm{W} / \mathrm{m}^{2}$ & 135 & 125 & 102 & 68 & 40 & 20 & 0,1 \\
\hline
\end{tabular}

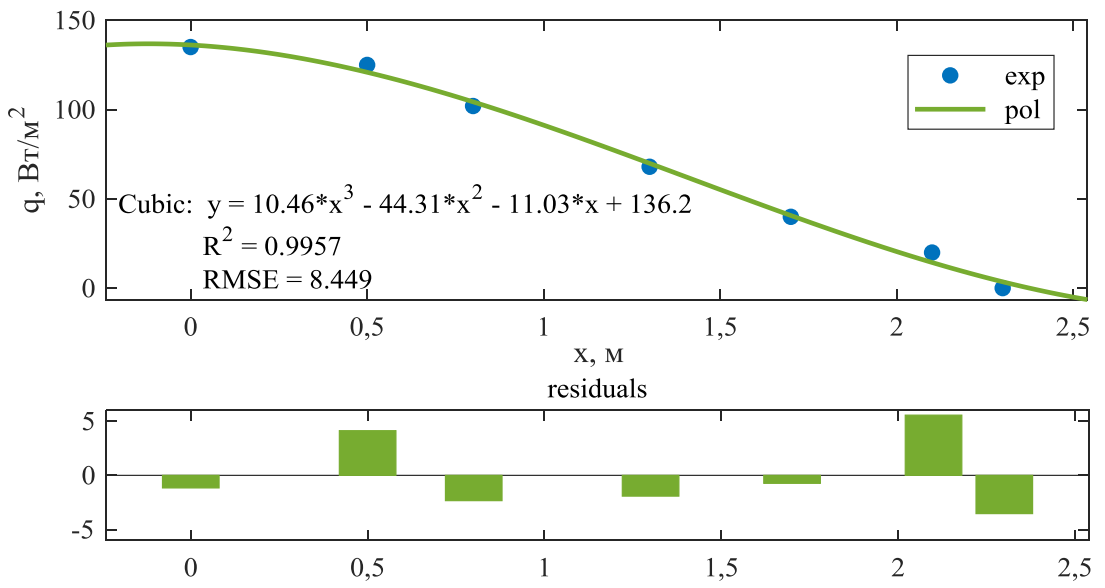

Pис. 10. Зависимость $q(X)$ : ехр - экспериментальные данные; pol- аппроксимационная кривая

Fig. 10. Dependence $q(X)$ : exp - experimental data; pol-approximation curve
Зависимость $\mathrm{q}(X)$ хорошо описывается полиномом третьей степени $q_{\mathrm{t}}(X)=10,07 X^{3}-43,34 X^{2}-12,19 X+136$ с величиной достоверной аппроксимации (Коэффициент детерминации) $\mathrm{R}^{2}=0,9973$ и среднеквадратичной ошибкой RMSE=6,651 (рис. 10).

Процесс переноса тепла в такой двухслойной пластине (рис. 9, $а$ ) описывается уравнением теплопроводности с соответствующими начальными и граничными условиями. 


$$
\begin{gathered}
\rho_{2} c_{2} \frac{\partial T_{2}}{\partial t}=\lambda_{2}\left(\frac{\partial^{2} T_{2}}{\partial x^{2}}+\frac{\partial^{2} T_{2}}{\partial z^{2}}\right), \\
0<x<l, 0<z<h_{1}, \\
\rho_{1} c_{1} \frac{\partial T_{1}}{\partial t}=\lambda_{1}\left(\frac{\partial^{2} T_{1}}{\partial x^{2}}+\frac{\partial^{2} T_{1}}{\partial z^{2}}\right), \\
0<x<l, \quad h_{1}<z<h_{1}+h,
\end{gathered}
$$

Начальные условия:

$$
T(x, z)=T_{0} .
$$

Граничные условия:

$$
\begin{gathered}
-\lambda \frac{\partial T}{\partial z}=q_{t}(x)+\alpha_{u}\left(T_{a i r}-T_{f}\right), \quad z=0,0<x<l,(4) \\
\quad \frac{\partial^{2} T}{\partial x^{2}}=0, x=0,0<z<h_{1}+h \\
-\lambda \frac{\partial T}{\partial x}=0, x=l, 0<z<h_{1}+h \\
-\lambda \frac{\partial T}{\partial z}=\alpha_{d}\left(T_{e}-T_{d}\right), z=h_{1}+h, 0<x<l \\
-T_{1}(t, x, z)=T_{2}(t, x, z) \\
\frac{\partial T_{1}}{\partial z}=-\lambda_{2} \frac{\partial T_{2}}{\partial z}, \quad z=h_{1}, 0<x<l
\end{gathered}
$$

где $x, z$ - координаты, м; $t$ - время, с; $T$ - температура, K; $T_{0}$ - температура в начальный момент времени, К; $T_{e}$ - температура окружающей среды, К; $T_{a i r}$ - температура воздуха внутри помещения, К; $T_{f}, T_{d}$ - температуры на верхней и нижней границах пола соответственно, К; $l$ - поперечный размер области решения, м; $h$ - толщина области решения, м; $\rho$ - плотность, кг $/ \mathrm{M}^{3} ; \lambda$ - коэффициент теплопроводности, Вт/(м·К); $c$ - теплоемкость, кДж/(кг·К); $\alpha_{u}, \alpha_{d}-$ коэффициенты теплоотдачи между поверхностью пола и воздухом на верхней и нижней границах соответственно, Вт/( $\left.\mathrm{M}^{2} \cdot \mathrm{K}\right)$, рассчитываются в соответствии с [25] для $\alpha_{u \text { : }}$ $\overline{N u}_{L}^{u}=0,15 R a_{L}^{1 / 3}$, для $\alpha_{d} \overline{N u}_{L}^{d}=0,52 R a_{L}^{1 / 5} ; \overline{N u}$ - среднее число Нуссельта; $R a$ - число Релея. Индексы 1 и 2 соответствуют материалам на рис. 9. Численные значения теплофизических характеристик материалов приведены в табл. 2.

Система уравнений теплопроводности (1), (2) с соответствующими начальными (3) и граничными (4)-(8) условиями решена методом конечных разностей с использованием неявной разностной схемы на равномерной сетке. Для решения системы алгебраических уравнений применялся метод прогонки $[10,11]$.

При численном решении задачи теплопереноса в однослойном бетонном полу (толщиной $h$ ) использовалось уравнение (2) с начальными и граничными условиями (3)-(7).

На рис. 11 представлены типичные результаты численного решения задачи (1)-(7).

Хорошо видно, что через 80 минут работы ГИИ пол прогревается на 0,16 м (от начальной температуры $17,5^{\circ} \mathrm{C}$ ), а максимальная температура его поверхности достигает $22,7^{\circ} \mathrm{C}$. Материал поверхности пола не оказывает существенного влияния на распределения температуры по толщине (теплофизические характеристики керамической плитки и бетона различаются незначительно). Если сравнить рассчитанные температуры поверхности пола с полученными экспериментально (рис. 12), видно их хорошее соответ-

\begin{tabular}{|c|c|c|c|c|c|c|c|}
\hline $\begin{array}{c}\text { Материал } \\
\text { Material }\end{array}$ & $\begin{array}{c}\lambda, \mathrm{BT} /(\mathrm{M} \cdot \mathrm{K}) \\
\mathrm{W} /(\mathrm{m} \cdot \mathrm{K})\end{array}$ & $\begin{array}{c}c, \mathrm{\kappa} \text { Дж/(кг·К) } \\
\mathrm{kJ} /(\mathrm{kg} \cdot \mathrm{K})\end{array}$ & $\begin{array}{c}\rho, \mathrm{\kappa} \Gamma / \mathrm{M}^{3} \\
\mathrm{~kg} / \mathrm{m}^{3}\end{array}$ & $\begin{array}{c}T_{0}, \\
\mathrm{~K}\end{array}$ & $\begin{array}{c}T_{e}, \\
\mathrm{~K}\end{array}$ & $\begin{array}{c}\alpha_{d}, \mathrm{BT} /\left(\mathrm{M}^{2} \cdot \mathrm{K}\right) \\
\mathrm{W} /\left(\mathrm{m}^{2} \cdot \mathrm{K}\right)\end{array}$ & $\begin{array}{c}\alpha_{u}, \mathrm{BT} /\left(\mathrm{M}^{2} \cdot \mathrm{K}\right) \\
\mathrm{W} /\left(\mathrm{m}^{2} \cdot \mathrm{K}\right)\end{array}$ \\
\hline Бетон/Concrete & 1,28 & 840 & 2000 & 290 & \multirow{2}{*}{258} & 4,45 & 7 \\
\hline Плитка/Tile & 1,5 & 750 & 2000 & 290 & & - & 7 \\
\hline
\end{tabular}
ствие в случае бетонного пола (рис. 12, б) во всем диапазоне изменения времени. В случае же керамической плитки до 40 мин отличия экспериментальных и рассчитанных значений $T_{f}$ составляют около $1{ }^{\circ} \mathrm{C}$ (рис. 12, а). Затем с ростом времени эта разность уменьшается (становится менее $0,2^{\circ} \mathrm{C}$ ).

Таблица 2. Теплофизические свойства материалов, характерные температуры и коэффициенты теплоотдачи между поверхностью пола и воздухом [25-28]

Table 2. Thermophysical properties of the materials, the characteristic temperatures and heat transfer coefficients between the floor surface and air [25-28]

$X, \mathrm{~m}$

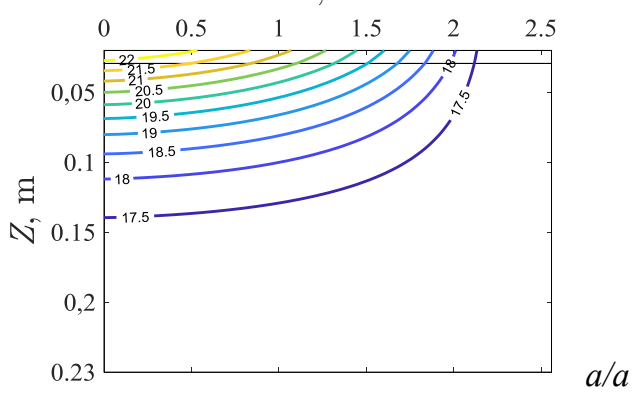

$X, \mathrm{~m}$

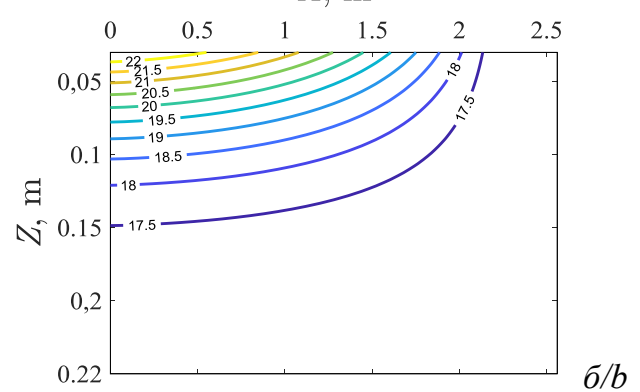

Pис. 11. Распределение температуры в области анализа при тепловом потоке, приведенном на рис. 10, в момент времени 80 мин: а) двухслойная пластина (бетон с керамическим покрытием), б) однослойная пластина (бетон)

Fig. 11. Temperature distribution in the analysis area at the heat flux shown in Fig. 10, at a time point of 80 minutes: a) a two-layer plate (concrete with a ceramic coating), b) a single-layer plate (concrete) 

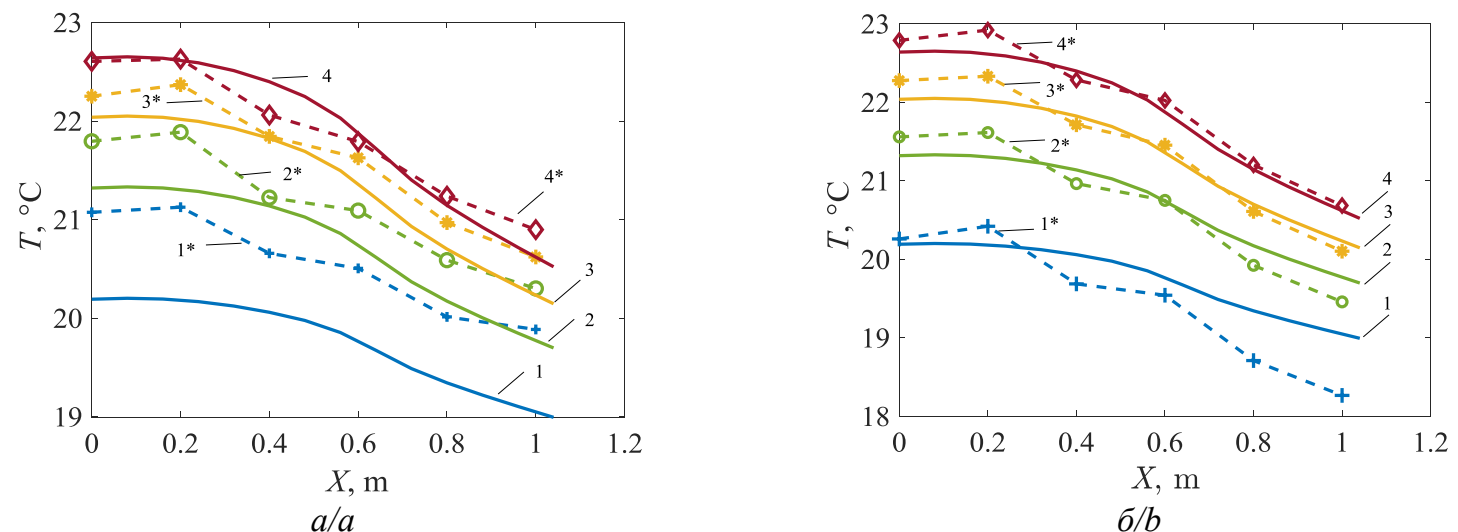

Рис. 12. Распределения температуры поверхности пола по направлению Х, полученные экспериментально (пунктирные линии) и в результате численного моделирования (сплошные линии) в разные моменты времени: а) двухслойный (бетон с керамическим покрытием), b) однослойный (бетон): 1 - 20 мин, 2 - 40 мин, 3 - 60 мин, $4-77$ мин

Fig. 12. Floor surface temperature distributions in the $X$ direction, obtained experimentally (a dashed line) and as a result of a numerical simulation (a solid line) at different time points: a) a two-layer (concrete with ceramic coating), $b$ ) a single-layer (concrete): 1 - $20 \mathrm{~min}, 2-40 \mathrm{~min}, 3-60 \mathrm{~min}, 4-77 \mathrm{~min}$

На рис 13. представлена динамика изменения средней температуры поверхности пола $(a)$ и теплового потока (б) от ГИИ (теплота затрачивается на нагрев воздуха рабочей зоны и на нагрев слоя пола).

Вычисление аккумулированной полом и воздухом теплоты в каждый момент времени $(\tau)$ проводилось по формулам:

$$
\begin{gathered}
Q_{\text {floor }}=\sum_{z=0}^{h} \sum_{x=0}^{l} \rho_{1} \cdot c_{1} \cdot\left(T_{1}-T_{0}\right) \cdot y \cdot h_{z} \cdot h_{x}, \\
Q_{\text {air }}=\sum_{t=0}^{\tau} \sum_{y=0}^{1} \sum_{x=0}^{l} \alpha_{u} \cdot\left(T_{f}-T_{e}\right) \cdot h_{y} \cdot h_{x} \cdot \Delta \tau,
\end{gathered}
$$

где $h_{x}, h_{y}, h_{z}$ - шаг по координатам $x, y$ и $z$ соответственно, м; $\Delta \tau$-шаг по времени, с.

Анализируя изменение средней по координате $X$ температуры поверхности во времени (рис. 13, a), можно заметить неплохое соответствие между численными и экспериментальными результатами. Ин-

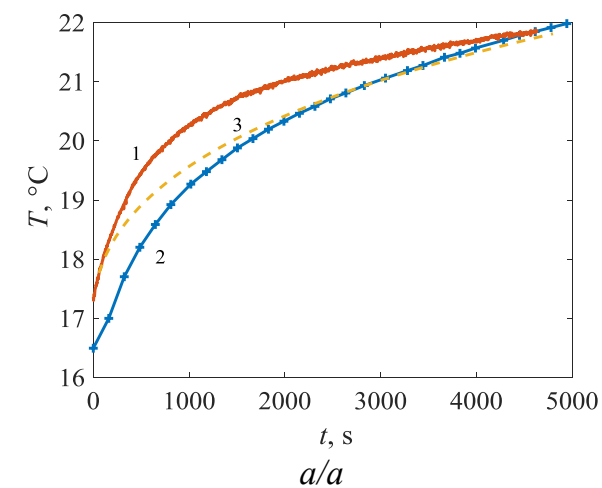

тенсивный рост температуры продолжается до 40 мин, после чего происходит снижение темпа этого роста.

Численный анализ показывает, что из всей теплоты, поступающей от ГИИ к напольному покрытию в начальный период (до 10 мин) времени (рис. 13, б), около $90 \%$ расходуется на нагрев пола и $10 \%$ - на нагрев воздуха рабочей зоны. С ростом времени их соотношение изменяется и становится $70 \% / 30 \%$.

На основании анализа результатов выполненных исследований можно сделать вывод что использование систем обеспечения теплового режима на базе ГИИ для локального обогрева рабочей зоны в закрытых помещениях являются энергоэффективными и экономичными. При этом часть теплоты (70 \%) (рис. 14), излучаемой ГИИ, расходуется на нагрев пола в локальной обогреваемой рабочей зоне, который в рассматриваемом случае является своеобразным аккумулятором энергии.

Рис. 13. Изменение средней температуры поверхности пола (по координате X) во времени (а) и тепловых потоков (б), при нагреве воздуха рабочей зоны (Air) и пола (Floor) во времени: 1 - экспериментальные значения для бетона с керамическим покрытием, 2 - экспериментальные значения для бетона, 3 - теоретические значения для двухслойной (бетон с керамическим покрытием) и однослойной пластины (бетон)

Fig. 13. Floor surface average temperature change over time (a) and heat fluxes (b), when the air of the working area (Air) and the floor (Floor) is heated over time: 1 - the experimental values for concrete with a ceramic coating, 2 - the experimental values for concrete, 3 - the theoretical values for a two-layer (ceramic-coated concrete) and one-layer plate (concrete) 


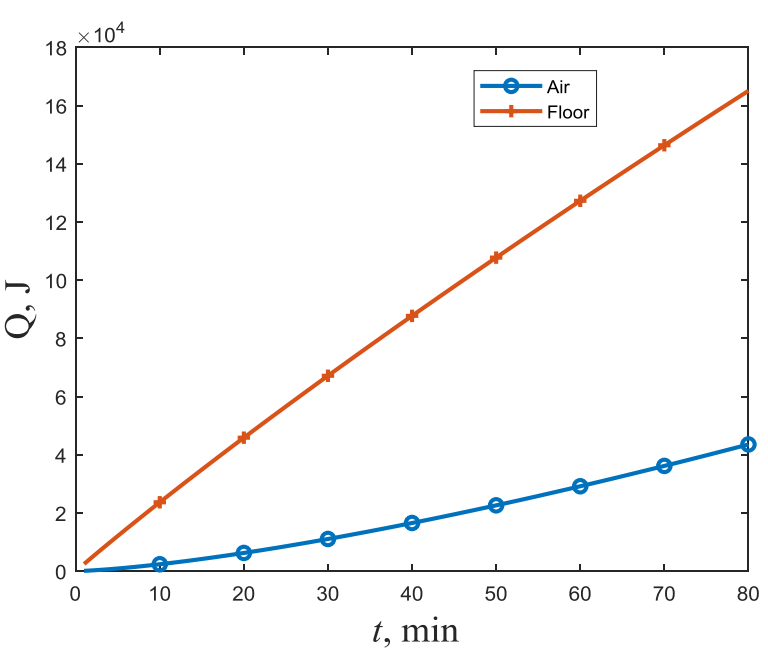

Рис. 14. Изменение количества теплоты, аккумулируемой полом $\left(Q_{\text {Floor }}\right)$ и воздухом $\left(Q_{\text {Air }}\right)$, поступающей от ГИИ

Fig. 14. Change in the amount of heat accumulated by the floor $\left(Q_{\text {Floor }}\right)$ and air $\left(Q_{\text {Air }}\right)$ coming from the gas infrared emitter

Целесообразно сравнение систем локального лучистого отопления с широко распространённым вариантом водяного отопления, использующегося в большинстве случаев для создания комфортных рабочих условий (например, заданной температуры) в производственных помещениях. В этом случае источник теплоты (как правило, радиаторы) нагревает воздух, а воздух в результате естественной конвекции в замкнутом объеме отдает большую часть тепла в ограждающие конструкции. При работе таких систем теплоснабжения значительная часть теплоты будет отводиться через ограждающие конструкции во внешнюю среду [29-35].

Для сравнения количества теплоты, необходимого для обеспечения регламентного теплового режима с использованием ГИИ и обычного водяного отопления решена задача теплопереноса в рассматриваемом объекте (рис. 15). Использована относительно простая, но обеспечивающая учет всех основных значимых факторов, математическая модель [36].

$$
\rho \cdot c \cdot \frac{d T}{d t}=Q_{1}-Q_{2}-Q_{3} ; \quad T(0)=T_{0},
$$

$Q_{1}$ - теплота, подводимая от источников системы водяного отопления; $Q_{2}$ - теплота, отводимая через поверхность ограждающей конструкции во внешнюю среду (условия вынужденной конвекции); $Q_{3}$ - теплота, отводимая через внутренние ограждающие конструкции (условие естественной конвекции) в воздух помещения.

В качестве примера рассмотрено производственное помещение относительно малых размеров $20 \times 15$ м, высотой 4 м с локальной рабочей зоной общей площадью $10 \mathrm{~m}^{2}$. При использовании ГИИ для обеспечения регламентного теплового режима (температура воздуха $23{ }^{\circ} \mathrm{C}$ [34]) необходим (как показали эксперименты) подвод теплоты от излучателя в эту зону с интенсивностью $Q=5$ кВт. Если же использо- вать обычное водяное отопление с расположенными на стенах радиаторами, то для нагрева воздуха (рис. 15) до такой же $\left(23^{\circ} \mathrm{C}\right)$ температуры во всем помещении и сохранения регламентного теплового режима в течении хотя бы рабочего времени (8 часов) необходим подвод $Q=28$ кВт в отапливаемое помещение. Такое значительное отклонение основных характеристик систем теплоснабжения обусловлено тем, что при таком расположении системы (рис. 15) водяного отопления необходим нагрев всего объема воздуха помещения $1200 \mathrm{~m}^{3}$ и (это главное) вынужденный нагрев всех ограждающих конструкций (стен и перекрытий), а не только пола (как в варианте с ГИИ). Важным при этом также является нестационарный характер теплоотвода в ограждающие конструкции.

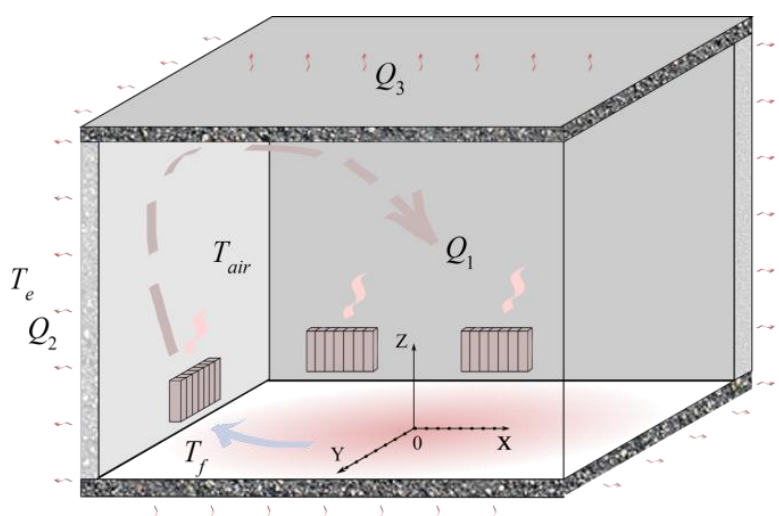

Pис. 15. Схематичное изображение помещения с водяным отоплением

Fig. 15. Schematic representation of the room with water heating

Системы водяного отопления (в отличии от систем лучистого нагрева) в отопительный сезон при отрицательных температурах внешней среды нельзя выключать - возможны аварийные ситуации. Поэтому водяное отопление должно работать круглосуточно (другие варианты в большинстве случаев невозможны). С целью оценки значений Q решена задача теплопереноса для области «воздух - ограждающие конструкции» при теплоотводе в окружающую среду в стационарном режиме $[31,33]$. В общем случае возможны различные варианты положения производственного помещения относительно окружающей среды. Так, например, теплоотвод может осуществляться с поверхности всех ограждающих конструкций (отдельно стоящее здание). Возможно размещение помещения внутри большого, но не отапливаемого здания. В этом случае теплоотвод с поверхностей внутренних ограждающих конструкций будет происходить с меньшей интенсивностью (отсутствие ветра). Но при низкой температуре за ограждающими конструкциями в соседних помещениях охлаждение воздуха в отапливаемом помещении за счет теплоотвода через внутренние стены также будет значимым, даже в условиях естественной конвекции $[34,36]$.

Соответственно, с увеличением объема помещений необходимая тепловая мощность источника может возрастать в десятки раз. При работе ГИИ ком- 
фортные условия для работающего достигаются в рабочей зоне достаточно быстро (через 20 минут после включения ГИИ, рис. 3,4$)$. При этом разность температур $1,5-2{ }^{\circ} \mathrm{C}$ на расстоянии $1-2$ м не является дискомфортной. Такой перепад температур формируется вследствие циркуляционного движения снизу вверх воздуха, нагреваемого теплым полом помещения. При водяном отоплении необходимое время для прогрева всего объема воздуха в помещении, ограждающих конструкций и оборудования, находящегося в нем (например, помещения с керамической плиткой для достижения температуры в воздухе $23{ }^{\circ} \mathrm{C}$ [34]) составляет как минимум 4,5 часа. С учетом того, что на нагрев воздуха (аккумулированнное тепло) тратится всего $1 \%$ тепловой энергии, поставляемой при водяном отоплении, а $99 \%$ расходуется на нагрев ограждающих конструкций, реальное время прогрева всего помещения для создания комфортных условий может составлять до суток.

Целесообразно уточнить, что ГИИ «подходят» не для отопления больших помещений, а только для обеспечения регламентного теплового режима в локальной рабочей зоне такого помещения. При этом эффективность системы лучистого отопления обусловлена не столько нагревом верхней части поверхности одежды работающего. Площадь этой поверхности около $0,1 \mathrm{M}^{2}$ и составляет менее $0,05 \%$ от общей площади воздействия радиационного потока, поступающего в рабочую зону от излучателя. Механизм нагрева воздуха в результате его термогравитационной конвекции установлен экспериментально [13] и обоснован теоретически [11]. Нагретый под действием лучистого потока пол помещения передает часть теплоты прилегающему к нему слою воздуха, который поднимается вверх и формирует циркуляционные течения в рабочей зоне. В результате холодный воздух верхних слоев этой зоны опускается вниз, нагревается в результате теплоотвода от поверхности пола и поднимается вверх, где охлаждается и опять опускается вниз. Излучение же напрямую может нагреть только малую часть поверхности одежды работающего, ориентированную перпендикулярно направлению лучистого теплового потока. Остальная часть поверхности одежды работающего участвует только в конвективном теплообмене с воздухом, окружающем работающего. Температура же последнего зависит от интенсивности термогравитационной конвекции, инициируемой нагретым полом. Ранее, в работах $[11,13]$, установлено, что при работе системы лучистого отопления в рабочей зоне формируется температурное поле с малым перепадом температур (рис. 3-8) - не более $2{ }^{\circ} \mathrm{C}$.

В заключение необходимо подчеркнуть, что преимущества системы отопления на базе ГИИ заключаются в следующем.

\section{СПИСОК ЛИТЕРАТУРЫ/REFERENCES}

1. Wang H., Kaur S., Elzouka M., Prasher R. A nano-photonic filter for near infrared radiative heater. Applied Thermal Engineering, 2019, vol. 153, pp. 221-224. Available at: https://doi.org/10.1016/ j.applthermaleng.2019.03.001 (accessed 15 August 2021).
1. При работе ГИИ нагревается только прилегающий к поверхности пола материал напольного покрытия и воздух рабочей зоны, которая по объему много меньше, как правило, общего объема помещения (в 10 и более раз). При работе же системы конвективного отопления нагревается не только тонкий слой вблизи поверхности пола, но все ограждающие вертикальные конструкции на всю толщину (чтобы обеспечить минимальный теплоотвод в окружающую среду с внешних поверхностей ограждающих конструкций) и перекрытия.

2. Также при работе системы конвективного отопления нагревается воздух не только в малом объеме локальной рабочей зоны, но и во всем помещении.

3. Кроме этого, для поддержания нормального теплового режима производственного помещения с системой конвективного отопления последняя должна работать круглосуточно. При работе же ГИИ регламентный тепловой режим локальной рабочей зоны устанавливается через 1-1,5 часа после начала работы излучателей. Соответственно, при односменной работе предприятия затраты энергии на работу ГИИ (без учета других перечисленных выше факторов) в 2-2,8 раза меньше по сравнению с затратами энергии на работу традиционных конвективных систем отопления.

Результаты выполненных экспериментальных и теоретических исследований дают основания для вывода о преимуществе (по сравнению с системами водяного отопления) в энергоэффективности систем лучистого отопления. При работе ГИИ вырабатываемая им теплота затрачивается на нагрев тонкого приповерхностного слоя пола и воздуха локальной рабочей зоны [37]. При работе систем водяного отопления вырабатываемая ими теплота затрачивается на нагрев не только приповерхностного слоя пола, но также вертикальных ограждающих конструкций и перекрытий. Кроме того, в последнем случае нагревается многократно больший объем воздуха по сравнению с системой лучистого отопления.

\section{Заключение}

В результате экспериментальных и теоретических исследований основных закономерностей процессов переноса теплоты в системе «газовый инфракрасный излучатель - воздух - пол» локальной рабочей зоны установлена достаточно высокая эффективность систем лучистого нагрева (газовых инфракрасных излучателей) при формировании тепловых режимов локальных рабочих зон, расположенных в производственных помещениях, характерные размеры которых и, соответственно, площади и объемы в десятки раз больше характерных размеров локальной рабочей зоны.

Работа выполнена при финансовой поддержке Российского Научного Фонда (проект № 20-19-00226).

2. Maznoy A., Kirdyashkin A., Pichugin N., Zambalov S., Petrov D. Development of a new infrared heater based on an annular cylindrical radiant burner for direct heating applications. Energy, 2020, vol. 204, article number 117965. Available at: https://doi.org/ 10.1016/j.energy.2020.117965 (accessed 15 August 2021). 
3. Lee E.-H., Yang D.-Y. Experimental and numerical analysis of a parabolic reflector with a radiant heat source. International Journal of Heat and Mass Transfer, 2015, vol. 85, pp. 860-864. Available at: https://doi.org/10.1016/j.ijheatmasstransfer.2015.02.042 (accessed 15 August 2021).

4. Brown K.J., Farrelly R., O’Shaughnessy S.M., Robinson A.J. Energy efficiency of electrical infrared heating elements. Applied Energy, 2016, vol. 162, pp. 581-588. Available at: https://doi.org/ 10.1016/j.apenergy.2015.10.064 (accessed 15 August 2021).

5. Rhee K.-N., Olesen B.W., Kim K.W. Ten questions about radiant heating and cooling systems. Building and Environment, 2017, vol. 112, pp. 367-381. Available at: https://doi.org/10.1016/ j.buildenv.2016.11.030 (accessed 15 August 2021).

6. Kurilenko N.I., Mamontov G.Ya., Mikhaylova L.Yu. Temperature patterns in the gas infrared radiator heating area. EPJ Web of Conferences, 2015, vol. 82, article number 01006. Available at: https://doi.org/10.1051/epjconf/20158201006 (accessed 15 August 2021).

7. Dudkiewicz E., Szałański P. Overview of exhaust gas heat recovery technologies for radiant heating systems in large halls. Thermal Science and Engineering Progress, 2020, vol. 18, article number 100522. Available at: https://doi.org/10.1016/ j.tsep.2020.100522 (accessed 15 August 2021).

8. Dudkiewicz E., Jeżowiecki J. The influence of orientation of a gas-fired direct radiant heater on radiant temperature distribution at a work station. Energy and Buildings, 2011, vol. 43, Iss. 6 , pp. 1222-1230. Available at: https://doi.org/10.1016/j.enbuild. 2010.12.030 (accessed 15 August 2021)

9. Sarbu I., Adriana Tokar A. Numerical modelling of hightemperature radiant panel heating system for an industrial hall. International Journal of Advanced and Applied Sciences, 2018, vol. 5 (5), pp. 1-9. Available at: https://doi.org/10.21833/ ijaas.2018.05.001 (accessed 15 August 2021).

10. Kuznetsov G.V., Maksimov V.I., Nagornova T.A. Prognostic potential of free convection models for analysis of thermal conditions of heat supply objects. Thermal Science, 2018, vol. 22, № 1B, pp. 545-556. Available at: https://doi.org/10.2298/TSCI150625104K (accessed 15 August 2021).

11. Kuznetsov G.V., Kurilenko N.I., Maksimov V.I., Mamontov G.Ya., Nagornova T.A. Heat transfer under heating of a local region of a large production area by gas infrared radiators. Journal of Engineering Physics and Thermophysics, 2013, vol. 86, pp. 519-524. Available at: https://doi.org/10.1007/s10891-013-0863-6 (accessed 15 August 2021)

12. Zajicek M., Kic P. Heating of large agricultural and industrial buildings. Agronomy Research, 2014, vol. 12 (1), pp. 237-244.

13. Kuznetsov G.V., Kurilenko N.I., Maksimov V.I., Nagornova T.A. Experimental and numerical study of heat transfer in production area heated by gas infrared source. International Journal of Thermal Sciences, 2020, vol. 154, article number 106396. Available at: https://doi.org/10.1016/j.ijthermalsci.2020.106396 (accessed 15 August 2021).

14. Kurilenko N. I., Kurilenko E.Yu., Mamontov G.Ya. New approach to microclimate parameter selection for the production area with heat supply systems based on gas infrared radiators. EPJ Web of Conferences, 2016, vol. 110, article number 01033. Available at: https://doi.org/10.1051/epjconf/201611001033 (accessed 15 August 2021).

15. Prek M., Krese G. Experimental analysis of an improved regulation concept for multi-panel heating radiators: Proof-ofconcept. Energy, 2018, vol. 161, pp. 52-59. Available at: https://doi.org/ 10.1016/j.energy.2018.07.107 (accessed 15 August 2021).

16. Pei Peng, Guangcai Gong, Xiaorui Deng, Chun Liang, Wenqiang Li. Field study and numerical investigation on heating performance of air carrying energy radiant air-conditioning system in an office. Energy and Buildings, 2020, vol. 209, article number 109712. Available at: https://doi.org/10.1016/j.enbuild.2019.109712 (accessed 15 August 2021).

17. Karl-Villem Võsa, Andrea Ferrantelli, Jarek Kurnitskia. A combined analytical model for increasing the accuracy of heat emission predictions in rooms heated by radiators. Journal of Building Engineering, 2019, vol. 23, pp. 291-300. Available at: https:// doi.org/10.1016/j.jobe.2019.02.009 (accessed 15 August 2021).
18. Guangcai Gong, Jia Liu, Xiong Mei. Investigation of heat load calculation for air carrying energy radiant air-conditioning system. Energy and Buildings, 2017, vol. 138, pp. 193-205. Available at: https://doi.org/10.1016/j.enbuild.2016.12.005 (accessed 15 August 2021).

19. Kavga A., Karanastasi E., Konstas I., Panidis Th. Performance of an infrared heating system in a production greenhouse. IFAC Proceedings, 2013, vol. 46, Iss. 18, pp. 235-240. Available at: https:// doi.org/10.3182/20130828-2-SF-3019.00017 (accessed 15 August 2021).

20. Chen Zhang, Michal Pomianowski, Per Kvols Heiselberg, Tao Yu. A review of integrated radiant heating/cooling with ventilation systems - thermal comfort and indoor air quality. Energy and Buildings, 2020, vol. 223, article number 110094. Available at: https://doi.org/10.1016/j.enbuild.2020.110094 (accessed 15 August 2021).

21. Kavga A., Alexopoulos G., Bontozoglou V., Pantelakis S., Panidis Th. Experimental investigation of the energy needs for a conventionally and an infrared heated greenhouse. Advances in Mechanical Engineering, 2012, article ID 789515, pp. 1-16. Available at: https://doi.org/10.1155/2012/789515 (accessed 15 August 2021).

22. ISO 11855. Building environment design - design, dimensioning, installation and control of embedded radiant heating and cooling systems, 2012.

23. ISO 7730. Moderate thermal environment - determination of the $P M V$ and PPD indices and specification of the conditions for thermal comfort. International organization for standardization. Geneva, Switzerland, 2005.

24. Jaluria Y. Natural convection heat and mass transfer. U.K., Pergamon Press, 1980. 326 p.

25. Bergman T.L., Lavine A.S., Incropera F.P., DeWitt D.P. Fundamentals of heat and mass transfer. $7^{\text {th }}$ ed. NY, John Wiley \& Sons, 2011. $1048 \mathrm{p}$.

26. DOE Fundamentals handbook, thermodynamics, heat transfer and fluid flow (Volume 2 of 3). U.S., Department of Energy, 2016. $80 \mathrm{p}$.

27. Haynes W.M. Handbook of chemistry and physics 2015-2016. Boca Raton, CRC/Taylor \& Francis, 2015. 3020 p.

28. Aliihsan Koca, Zafer Gemici, Yalcin Topacoglu, Gursel Cetin, Rusen Can Acet, Baris Burak Kanbur. Experimental investigation of heat transfer coefficients between hydronic radiant heated wall and room. Energy and Buildings, 2014, vol. 82, pp. 211-221. Available at: https://doi.org/10.1016/j.enbuild.2014.06.045 (accessed 15 August 2021).

29. Derbal R., Defer D., Chauchois A., Antczak E. A simple method for building materials thermophysical properties estimation, Construction and Building Materials, 2014, vol. 63, pp. 197-205. Available at: https://doi.org/10.1016/j.conbuildmat.2014.04.076 (accessed 15 August 2021)

30. Obyn S., Van Moeseke G. Variability and impact of internal surfaces convective heat transfer coefficients in the thermal evaluation of office buildings. Applied Thermal Engineering, 2015, vol. 87, pp. 258-272. Available at: https://doi.org/10.1016/ j.applthermaleng.2015.05.030 (accessed 15 August 2021).

31. Pedersen C.O., Fisher D.E., Liesen R.J. Development of a heat balance procedure for calculating cooling loads. ASHRAE Transactions, 1997, vol. 103, Pt. 2, pp. 459-468.

32. Cengel Yu.A., Chajar A.J. Heat and mass transfer, fundamentals and applications. $4^{\text {th }}$ ed. New York, McGraw-Hill, 2011. $905 \mathrm{p}$.

33. Wang S., Xiao L.F., Yan C. Quantitative energy performance assessment methods for existing buildings. Energy and Buildings, 2012, vol. 55, pp. 873-888. Available at: https://doi.org/ 10.1016/j.enbuild.2012.08.037 (accessed 15 August 2021).

34. Yan C., Wang S., Shan K., Lu Y. A simplified analytical model to evaluate the impact of radiant heat on building cooling load. Applied Thermal Engineering, 2015, vol. 77, pp. 30-41. Available at: https://doi.org/10.1016/j.applthermaleng.2014.12.017 (accessed 15 August 2021).

35. Veselý M., Kramer R., Zeiler W. Energy performance of personalized heating: numerical case study for a medium sized office building including different envelope qualities and climates. Journal of Building Engineering, 2018, vol. 21, pp. 113-119. Available at: https://doi.org/10.1016/j.jobe.2018.10.008 (accessed 15 August 2021). 
36. Wang D., Wu C., Liu Y., Chen P., Liu J. Experimental study on the thermal performance of an enhanced-convection overhead radiant floor heating system, Energy and Buildings, 2017, vol. 135, pp. 233-243. Available at: https://doi.org/10.1016/ j.enbuild.2016.11.017 (accessed 15 August 2021).

37. Dudkiewicz E., Jeżowiecki J. Measured radiant thermal fields in industrial spaces served by high intensity infrared heater. Energy and Buildings, 2009, vol. 41, Iss. 1, pp. 27-35. Available at: https://doi.org/10.1016/j.enbuild.2008.07.005 (accessed 15 August 2021).

\section{Информация об авторах}

Максимов В.И., кандидат технических наук, доцент Научно-образовательного центра И.Н. Бутакова Инженерной школы энергетики Национального исследовательского Томского политехнического университета.

Нагорнова Т.A., кандидат технических наук, доцент Научно-образовательного центра И.Н. Бутакова Инженерной школы энергетики Национального исследовательского Томского политехнического университета.

Куриленко Н.И., кандидат физико-математических наук, профессор кафедры теплогазоснабжения и вентиляции Строительного института Тюменского индустриального университета.

Волошко И.В., ведущий инженер «Теплотранзит Караганда». 
UDC 62-6

\title{
ADVANTAGE ANALYSIS OF SYSTEMS FOR ENSURING LOCAL WORKING ZONES THERMAL CONDITIONS BASED ON GAS INFRARED EMITTERS IN COMPARISON WITH TRADITIONAL CONVECTIVE HEATING SYSTEMS
}

\author{
Vyacheslav I. Maksimov'1, \\ elf@tpu.ru
}

\section{Tatiana A. Nagornova ${ }^{1}$,} tania@tpu.ru

\author{
Nikolay I. Kurilenko², \\ kurilenkoni@tyuiu.ru \\ Ivan V. Voloshko ${ }^{3}$, \\ iv_voloshko@mail.ru \\ 1 National Research Tomsk Polytechnic University, \\ 30, Lenin avenue, Tomsk, 634050, Russia. \\ 2 Industrial University of Tyumen, \\ 38 , Volodarsky street, Tyumen, 625000 , Russia. \\ 3 «Teplotranzit Karaganda», \\ 9/2, Suburban street, Karaganda, 100017, Kazakhstan.
}

The relevance of the study is caused by the decrease in thermal energy consumption to ensure the thermal conditions of local working zones in industrial premises, the characteristic dimensions of which significantly (many times) exceed these zone dimensions. The problems of energy conservation have been relevant for many decades for a number of objective reasons. However, so far there is no occasion to conclude that most of the issues arising in the production and social spheres have been solved. The well-known method of local «heat supply» of a relatively small workplace with the use of gas infrared emitters until recently has been little used due to the lack of a scientific and technical base that provides experimental design work to create systems for ensuring the thermal conditions of local workplaces based on gas infrared emitters.

Aim: analysis of the energy efficiency of gas infrared emitters as the main elements of systems for ensuring the thermal conditions of local working zones.

Objects: a large room heated by a gas infrared emitter.

Methods: experimental measurements of floor surface temperatures with chromel-alumel type thermocouples with a junction thickness of $0,08 \mathrm{~mm}$ and data recording using the NI 9214 temperature measurement module from National Instruments; mathematical modeling of heat transfer processes in a multilayer floor.

Results. The article presents the results of experimental and theoretical studies carried out to assess the effectiveness of using such systems. The experiments were carried out in a special box that reproduces the conditions for supplying heat from the emitter to a small workplace. The floor surface temperature was measured at ten characteristic points during typical averaged power emitter operation. The experimental results were used as boundary conditions at the "air - box floor surface» interface when solving heat conduction problems. Based on the results of experimental and theoretical studies, the advantages (in comparison with traditional convective heating systems of even small-sized industrial premises) of systems based on gas infrared emitters for ensuring the thermal conditions of local working zones are substantiated. The essence of these advantages lies in the fact that when using emitters, the routine thermal conditions is provided without energy consumption for heating the enclosing structures and air outside the working area (which can be ten times smaller in terms of the entire industrial premise volume).

Key words:

Energy saving, gas infrared emitters, heat transfer, thermocouple measurements, temperature distribution, energy efficiency.

The research was financially supported by the Russian Science Foundation (project no. 20-19-00226).

Information about the authors

Vyacheslav I. Maksimov, Cand. Sc., associate professor, National Research Tomsk Polytechnic University. Tatiana A. Nagornova, Cand. Sc., associate professor, National Research Tomsk Polytechnic University. Nikolay I. Kurilenko, Cand. Sc., professor, Industrial University of Tyumen.

Ivan V. Voloshko, leading engineer, «Teplotranzit Karaganda». 